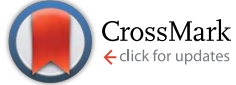

Cite this: J. Mater. Chem. A, 2015, 3, 13203

Received 1st April 2015

Accepted 13th May 2015

DOI: 10.1039/c5ta02381e

www.rsc.org/MaterialsA

\section{Microwave shielding properties of Co/Ni attached to single walled carbon nanotubes $\uparrow$}

\author{
B. P. Singh, * D. K. Saket, A. P. Singh, Santwana Pati, T. K. Gupta, V. N. Singh, \\ S. R. Dhakate, S. K. Dhawan, R. K. Kotnala and R. B. Mathur
}

Cobalt/nickel nanoparticles attached to single-walled carbon nanotubes (Co/Ni@SWCNTs) were prepared by dc-arc discharge technique. Co/Ni@SWCNTs were characterized by scanning electron microscopy, high resolution transmission electron microscopy (HRTEM), Raman spectroscopy and energy dispersive X-ray analysis techniques. HRTEM results confirmed attachment of magnetic nanoparticles onto SWCNTs having $1.2 \mathrm{~nm}$ diameter. A microwave shielding effectiveness value of $24 \mathrm{~dB}$ (blocking $>99 \%$ radiation) by a $1.5 \mathrm{~mm}$ thick sample in the frequency range of $12.4-18 \mathrm{GHz}$ was observed. In order to understand the mechanism of shielding, dielectric and magnetic attributes of the shielding effectiveness of $\mathrm{Co} /$ NiaSWCNTs have been evaluated. Eddy currents and natural resonances due to the presence of magnetic nanoparticles, electronic polarization and their relaxation, interfacial polarization and unique composition of the shield contributed significantly in achieving good shielding effectiveness. The observed microwave shielding crossed the limit required for commercial applications which suggests that these nanocomposites are promising microwave shielding materials in the Ku band.

\section{Introduction}

Carbon based composites have gained significant popularity as microwave shielding materials because of their low density, facile synthesis and ease of processing. Recently, research on carbon containing nanomaterials has taken a leap. ${ }^{\mathbf{1}}$ In general, there are two practical ways for electromagnetic wave shielding by materials; the first is to protect certain components from the radiation by reflecting the waves and the other is to reduce the reflection and increase the absorption by incorporating dielectric or magnetic particles into it. ${ }^{2}$ On account of their ability to

CSIR-National Physical Laboratory, Dr K.S. Krishnan Marg, New Delhi-110012, India. E-mail: bps@nplindia.org; bpsingh2k4@yahoo.com; Fax: +91-11-45609310; Tel: +9111-45608460

$\dagger$ Electronic supplementary information (ESI) available: See DOI: 10.1039/c5ta02381e reduce electromagnetic wave pollution and radar signatures, microwave shielding materials which can absorb in the frequency range of 1-20 GHz are in high demand for civil as well as military applications. ${ }^{3}$

For microwave absorption in the high frequency range (over gigahertz) soft magnetic metallic materials are considered better than traditional ferrite absorbers. Nevertheless, the relative complex permeability of magnetic metallic materials decreases due to eddy currents induced by electromagnetic waves. Thus, it may be better to use isolated metallic particles having sizes smaller than the skin depth of electromagnetic waves into the materials. ${ }^{4}$ Therefore, research on various materials, e.g., $\mathrm{Fe}_{3} \mathrm{~B} / \mathrm{Y}_{2} \mathrm{O}_{3},{ }^{5}$ rare earth lanthanum nitrate doped amorphous carbon nanotubes (CNTs), ${ }^{6} \quad \mathrm{Fe} / \mathrm{CNTs}^{7,8}$ and $\mathrm{CoFe}_{2} \mathrm{O}_{4} / \mathrm{CNT}^{9}$ composites has been carried out by various researchers.

Recently, MWCNTs ${ }^{10-14}$ have been explored as a potential candidate for developing microwave shielding materials and thus have opened a new avenue for investigating applications of other carbon materials in shielding. Smaller diameter, higher aspect ratio, good conductivity and higher mechanical strength of CNTs make them an excellent candidate for producing conductive composites useful for high performance EMI shielding materials at lower filling. ${ }^{11,12}$ The mechanical properties of CNTs have drawn intense interest for their usefulness as reinforcement materials in composites.

Shielding effectiveness (SE) of any shield is governed by its dielectric attributes, magnetic permeability, thickness and frequency of incident radiation. The absorption loss depends on the value of $\varepsilon_{\mathrm{r}} / \mu_{\mathrm{r}}$, and the absorption loss is maximum when $\mu_{\mathrm{r}}=\varepsilon_{\mathrm{r}}{ }^{15}$ The presence of magnetic materials helps in matching of $\varepsilon_{\mathrm{r}}$ and $\mu_{\mathrm{r}}$ which is necessary for enhancing the absorption of EM waves. However, to the best of our knowledge, SWCNTs in EMI SE applications have not been thoroughly explored to date.

Single walled carbon nanotubes (SWCNTs) have been explored for several applications; energy storage and harvesting, electronic appliances, and biomedical applications. But, the exploration for microwave absorption and microwave shielding 
is still limited. Microwave absorption properties of SWCNT/polyurethane composites in the frequency range of 2-18 GHz have been studied by Liu et al. ${ }^{16}$ and a maximum absorption value of $22 \mathrm{~dB}$ for $5 \mathrm{wt} \%$ SWCNTs in polyurethane has been observed. Huang et al. have reported an EMI-SE of $18 \mathrm{~dB}$ for composites with $15 \mathrm{wt} \%$ small SWCNTs and 23-28 dB for composites with $15 \mathrm{wt} \%$ long SWCNTs in the frequency band of 8-12.4 GHz. ${ }^{17}$ Li et al. ${ }^{18}$ reported EMI shielding properties of SWCNT epoxy composites and showed an EMI shielding effectiveness of $15-20 \mathrm{~dB}$ in the $500 \mathrm{MHz}$ to $1.5 \mathrm{GHz}$ frequency range and $49 \mathrm{~dB}$ at $10 \mathrm{MHz}$ frequency. Wadhwan et al. ${ }^{19}$ have reported better microwave absorption properties of unpurified SWCNTs possessing magnetic Fe nanoparticle impurities (due to the cooperative effect). Srivastava et al. reported flexible, non-corrosive and light weight nickel nanoparticle MWCNT-polystyrene composite films as good microwave absorbing materials in the frequency range of the $\mathrm{S}$ band $(2-4 \mathrm{GHz}) .^{20}$ Recently, Co decorated MWCNTs have also been used as microwave absorbing materials. ${ }^{21}$ To the best of our knowledge, there is no study on the microwave absorption or microwave shielding by $\mathrm{Co} / \mathrm{Ni}$ nanoparticle attached SWCNTs.

Binary mixtures of active catalysts such as $\mathrm{Ni}, \mathrm{Fe}$ and Co are frequently used and often observed to display a higher activity than individual elements, resulting in better quality and higher yield of SWCNTs. Therefore, in this study, $\mathrm{Co} / \mathrm{Ni}$ attached SWCNTs (Co/Ni@SWCNTs) were synthesized by the dc-arc discharge technique using a mixture of Co and $\mathrm{Ni}$ as catalysts. This was done by arcing graphite in the presence of $\mathrm{Co} / \mathrm{Ni}$ and their microwave shielding properties were investigated. It has been shown that even a $1.5 \mathrm{~mm}$ thick sheet of as-produced Co/Ni@SWCNTs can act as an efficient microwave shielding material.

\section{Experimental}

Co/Ni@SWCNTs were synthesized by the dc-arc discharge process. A high density graphite block (purity: 99.9\%) was machined to a $10 \mathrm{~mm}$ (dia.) solid cylinder and used as the cathode. The anode was a hollow graphite cylinder which was filled with $\mathrm{Co} / \mathrm{Ni}$ and graphite powders. The anode used for arcdischarge had a length of $100 \mathrm{~mm}$, outer diameter of $8 \mathrm{~mm}$, inner diameter of $6.5 \mathrm{~mm}$, and drilled depth of $80 \mathrm{~mm}$. A mixture of $\mathrm{Ni}$ and Co powders ( 2 at\% each, purity: $>99.9 \%$, average particle size: $<3 \mu \mathrm{m}$, Aldrich) were used as the catalyst and were ball milled along with graphite powder and filled into the hole (dia. $6.5 \mathrm{~mm}$ ) drilled in the graphite anode. For maintaining a stable arc-discharge, a uniform gap of 1-2 mm was maintained between the electrodes with the help of a

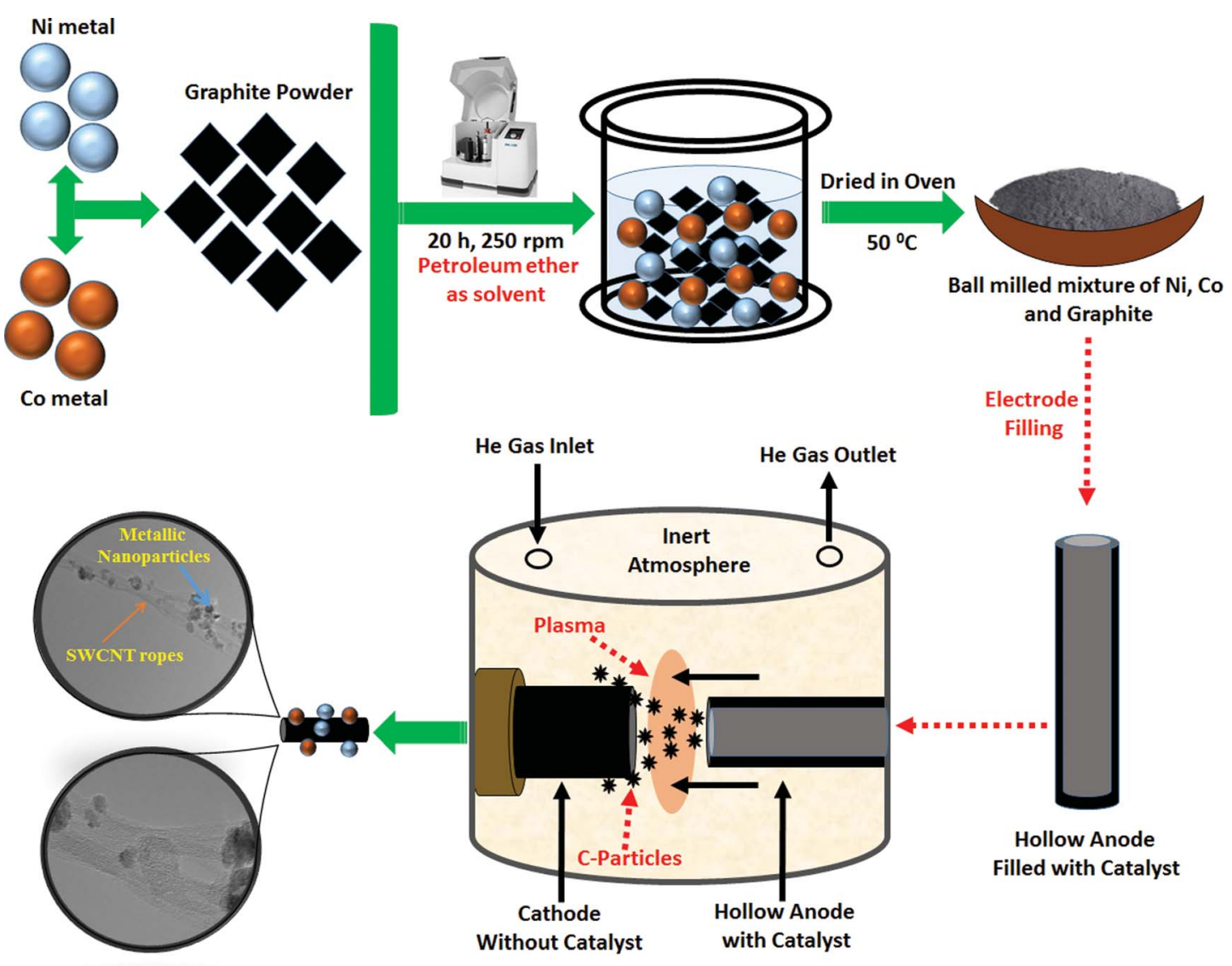

Fig. 1 Schematic showing synthesis of Co/Ni@SWCNT by the dc-arc discharge method. 
stepper motor. de voltage of 20-25 V, current of 100-120 A and helium pressure of 600 torr were used. A schematic for the synthesis of Co/Ni@SWCNTs is shown in Fig. 1.

\section{Results and discussion}

The scanning electron microscopic (SEM) image of the grown material shown in Fig. 2a reveals the presence of carbon nanotubes. High resolution transmission electron microscopic (HRTEM) images shown in Fig. $2 b$ and $c$ reveal the presence of metallic nanoparticles over SWCNTs. The Raman spectrum of this material has a peak at $185 \mathrm{~cm}^{-1}$ corresponding to radial breathing mode of SWCNTs (shown in Fig. 2d).

According to Araujo et al. ${ }^{22}$ diameters of SWCNTs can be estimated using the following relationship,

$$
\omega_{\mathrm{rbm}}=227 / d_{\mathrm{t}}
$$

where, $\omega_{\text {rbm }}$ is the Raman shift $\left(\mathrm{cm}^{-1}\right)$ and $d_{\mathrm{t}}$ is the tube diameter of CNT (in nm). Fig. 2e shows the EDX spectra of Co/ Ni@SWCNTs, where the presence of Co, Ni, carbon and oxygen can be seen. HRTEM image of SWNCTs and SAED pattern of Co/ $\mathrm{Ni}$ attached to SWCNTs are shown in Fig. S1 and S2 (see the ESI $\dagger$ ).

Room temperature field dependence magnetic properties of Co/Ni@SWCNTs have been studied by plotting the $\mathrm{M}-\mathrm{H}$ curve and the results are shown in Fig. 3a. The saturation magnetization $\left(M_{\mathrm{s}}\right)$ value for the $\mathrm{Co} / \mathrm{Ni} @ S W C N T$ s synthesized by the arcdischarge method was $\sim 12.25 \mathrm{emu}^{-1}$ at an external applied field of $5 \mathrm{kOe}$. The $\mathrm{M}-\mathrm{H}$ curve shows a very small value for coercivity and a negligible value for retentivity (without any hysteresis loop), indicating a superparamagnetic nature (as shown in the inset of Fig. 3a). The pristine SWCNT is nonmagnetic in nature and therefore the observed magnetization in $\mathrm{Co} / \mathrm{Ni} @ S W C N T s$ is attributed to the presence of high wt $\%$ of Co and $\mathrm{Ni}$ on SWCNTs. Furthermore, the observed magnetic behavior of Co/Ni@SWCNTs is supposed to be helpful in achieving a higher shielding effectiveness (SE) value suitable for EMI shielding applications.

To further understand the mechanism of EMI shielding, dielectric measurements of the composite were carried out using an Agilent E8362B Vector Network Analyzer. The powder of Co/Ni@SWCNTs was pressed into a rectangular shape of $22.8 \times 10 \mathrm{~mm}^{2}$. The rectangular shaped samples with different thicknesses were inserted into the copper sample holder placed between the wave-guides. The $S$ parameters, $S_{i j}\left\{S_{11}\left(S_{22}\right), S_{12}\right.$ $\left.\left(S_{21}\right)\right\},{ }^{18}$ were recorded using a vector network analyzer (VNA E8263B Agilent Technologies) in the frequency range of 12.4-18 $\mathrm{GHz}$ (Ku band) via two port measurement techniques. The transmission coefficient $(T)$ and reflection coefficient $(R)$ were calculated using the equations,

$$
\begin{aligned}
& T=\left|\frac{E_{\mathrm{T}}}{E_{\mathrm{I}}}\right|^{2}=\left|S_{21}\right|^{2}=\left|S_{12}\right|^{2} \\
& R=\left|\frac{E_{\mathrm{R}}}{E_{\mathrm{I}}}\right|^{2}=\left|S_{11}\right|^{2}=\left|S_{22}\right|^{2}
\end{aligned}
$$

and the absorption coefficient can be expressed in terms of $R$ and $T$ as $(A)=1-R-T$.

Absorption efficiency (AE) can be obtained using the relationship $\mathrm{AE}=A /(1-R) \times 100 \%$.

EMI SE of any material is the sum of contributions from absorption $\left(\mathrm{SE}_{\mathrm{A}}\right)$, reflection $\left(\mathrm{SE}_{\mathrm{R}}\right)$ and multiple reflections $\left(\mathrm{SE}_{\mathrm{M}}\right)$ of the $\mathrm{EM}^{23-26}$ as per the equation,

$$
\mathrm{SE}(\mathrm{dB})=\mathrm{SE}_{\mathrm{R}}+\mathrm{SE}_{\mathrm{A}}+\mathrm{SE}_{\mathrm{M}}=-10 \log \left(P_{\mathrm{T}} / P_{\mathrm{I}}\right)
$$

where, $P_{\mathrm{I}}$ and $P_{\mathrm{T}}$ are the power of incident and transmitted EM waves, respectively. According to Schelkunoff's theory, $\mathrm{SE}_{\mathrm{M}}$ can be ignored for all practical purposes when the shield is thicker than the skin depth $(\delta)$ of the material. Furthermore, $\mathrm{SE}_{\mathrm{R}}$ and $\mathrm{SE}_{\mathrm{A}}$ can be calculated using equations, $\mathrm{SE}_{\mathrm{R}}=-10 \log (1-R)$ and $\mathrm{SE}_{\mathrm{A}}=-10 \log \left(1-A_{\text {eff }}\right)=-10 \log (T / 1-R)$.

For a material, the skin depth $(\delta)$ is the distance up to which the intensity of the EM wave decreases to $1 / e$ of its original strength. $\delta$ is related to angular frequency and relative permeability through the relationship $\delta=\sqrt{2 / \sigma \omega \mu^{\prime}} \sigma_{\text {ac }}=\omega \varepsilon_{0} \varepsilon^{\prime \prime}$ (see ESI Fig. S3 $\dagger$ ). Determination of the critical thickness of the shield and its variation with frequency is shown in the ESI (Fig. S4 $\dagger$ ). It should be noted that the skin depth for SWCNTs is $\sim 1 \mathrm{~mm}$. This means that the shield should have a thickness greater than $\sim 1 \mathrm{~mm}$.

Fig. 3c shows the variation of SE with frequency in the 12.4-18 $\mathrm{GHz}$ range. The values of $\mathrm{SE}$ due to absorption $\left(\mathrm{SE}_{\mathrm{A}}\right)$ are: -10.5 $\mathrm{dB},-12.5 \mathrm{~dB}$ and $-19.5 \mathrm{~dB}$ for thicknesses of 1.00, 1.25 and 1.50 $\mathrm{mm}$, respectively. Thus, $\mathrm{SE}_{\mathrm{A}}$ increases with increase in thickness. On the other hand, the values of $\mathrm{SE}_{\mathrm{R}}$ are: -2.0 to $4.5 \mathrm{~dB}$ and -4.5 $\mathrm{dB}$, respectively. Therefore, the total SE for thicknesses of 1.00, 1.25 and $1.50 \mathrm{~mm}$ are: $-12.5,-17.0$ and $-24.0 \mathrm{~dB}$, respectively. Thus, SE is mainly dominated by absorption as usually reported for such materials. It is to be noted that the value of SE for a critical thickness of $1.5 \mathrm{~mm}$ is greater than the limit required for commercial applications $(\sim-20 \mathrm{~dB})$.

The obtained SE results can be explained in terms of electromagnetic attributes $\left(\varepsilon^{*}\right.$ and $\left.\mu^{*}\right)$ of Co/Ni@SWCNTs. The complex permittivity $\left(\varepsilon^{*}=\varepsilon^{\prime}-i \varepsilon^{\prime \prime}\right)$ and complex permeability $\left(\mu^{*}=\mu^{\prime}-i \mu^{\prime \prime}\right)$ have been calculated using the experimental scattering parameters $\left(S_{11}\right.$ and $\left.S_{21}\right)$ by means of standard Nicholson-Ross and Weir theoretical calculations. ${ }^{27}$ The results are shown in Fig. $3 \mathrm{~b}$. In short, permittivity $\left(\varepsilon^{\prime}\right)$ and permeability $\left(\mu^{\prime}\right)$ account for the amount of polarization in the material and symbolize the storage ability of the electric and magnetic energy. The permittivity $\left(\varepsilon^{\prime \prime}\right)$ and permeability loss $\left(\mu^{\prime \prime}\right)$ reveal the dissipated electric and magnetic energies, respectively. As shown in Fig. $3 \mathrm{~b}$, the values of $\varepsilon^{\prime}, \varepsilon^{\prime \prime}, \mu^{\prime}$ and $\mu^{\prime \prime}$ lie in the ranges of 22.2-26.5, 19.3-22.9, 1.12-1.20 and 0.16-0.12, respectively, i.e., in the Ku-band frequency range. The observed permittivity $\left(\varepsilon^{\prime}\right)$ is due to conductivity, electronic polarization, dipole polarization as well as interfacial polarization. Similarly, dielectric losses $\left(\varepsilon^{\prime \prime}\right)$ are the result of electronic polarization and its relaxation, dipole relaxation, natural resonances and structure of the shield. Interfacial polarization in heterogeneous media is due to accumulation of charges at the interfaces and formation of dipoles. Interfaces among SWCNTs, Co 

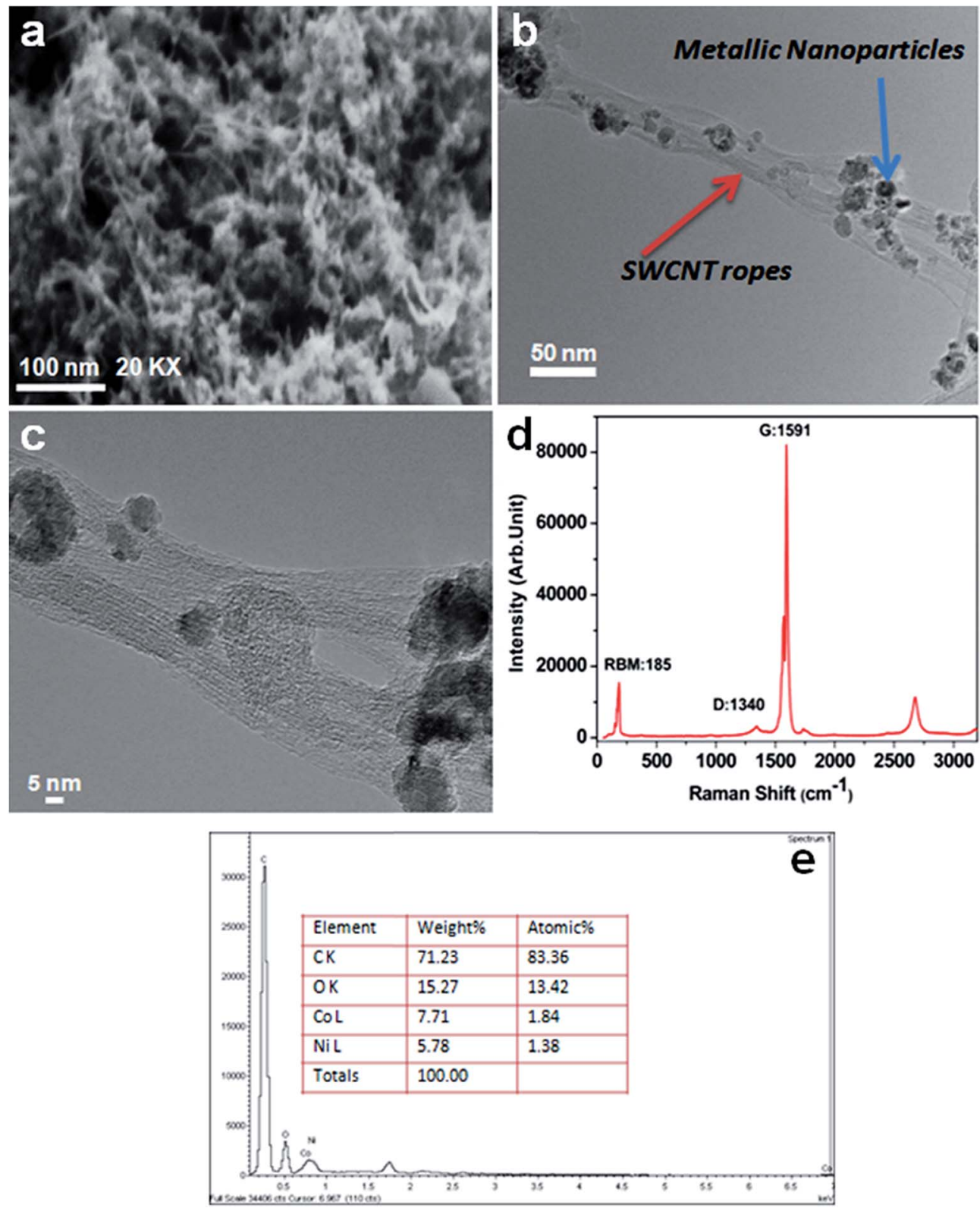

Fig. 2 (a) SEM image, (b and c) HRTEM images, (d) Raman spectrum and (e) EDX of Co/Ni@SWCNTs.

nanoparticles, and Ni nanoparticles further contribute to the dielectric losses. The ballistic electrons in the SWCNTs cannot reorient themselves fast enough when an external electric field is applied. Magnetic nanoparticles of $\mathrm{Co} / \mathrm{Ni}$ present on SWCNTs act as the polarization centre and contribute towards better microwave absorption. Higher aspect ratio and good conductivity of SWCNTs also enhance the absorption properties. The observed permeability is due to the presence of $\mathrm{Co} / \mathrm{Ni}$ magnetic nanoparticles which act as tiny dipoles and get polarized in the presence of an electromagnetic field resulting in better microwave shielding. Furthermore, eddy currents due to magnetic particles and natural resonance caused by the enhanced surface anisotropy of the small sized $\mathrm{Co} / \mathrm{Ni}$ nanoparticles also contribute towards better absorption. Anisotropy energy of the nanosized materials would be higher due to the surface anisotropic field. ${ }^{28,29}$ The higher anisotropy energy also contributes towards the enhancement of the microwave absorption. Several mechanisms for enhanced EMI shielding and microwave absorption by CNT based materials have been proposed earlier. ${ }^{30-32}$

Thus, the excellent microwave absorbing performance by Co/Ni@SWCNTs is mainly attributed to the impedance matching and microwave attenuation. For a perfect absorber, $\varepsilon_{\mathrm{r}}=\mu_{\mathrm{r}}$ or $\varepsilon_{\mathrm{r}} / \mu_{\mathrm{r}}=1$. The presence of super-paramagnetic Co and Ni nanoparticles on SWCNTs helped in lowering the $\varepsilon_{\mathrm{r}} / \mu_{\mathrm{r}}$ ratio resulting in improved impedance matching. ${ }^{29}$ In order to provide a visual demonstration of the microwave shielding mechanism (as discussed above), a schematic diagram has been shown in Fig. 4. The above results prove that Co/Ni@SWCNTs could be potentially used as microwave shielding materials. 

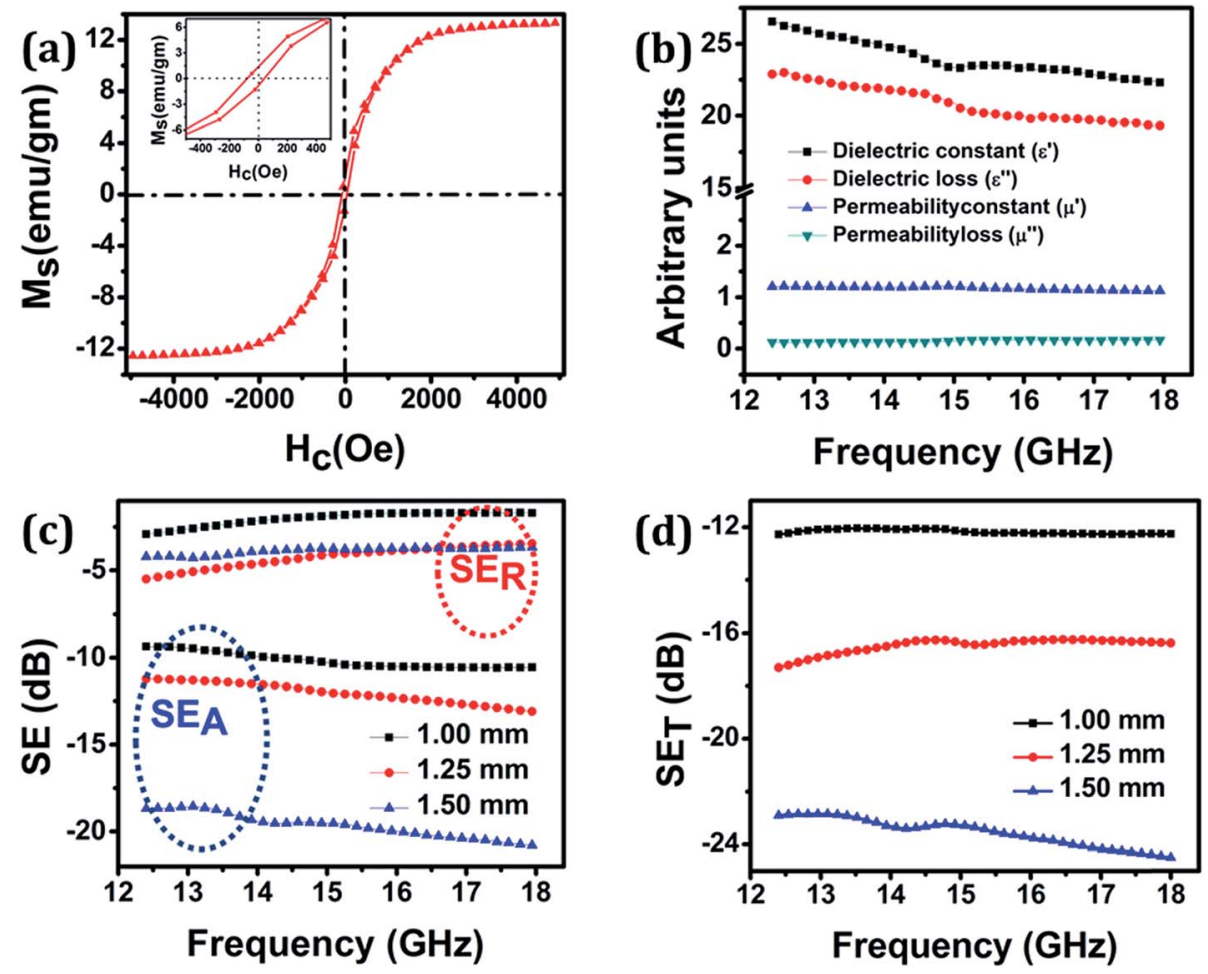

Fig. 3 (a) M-H curve for Co/NiaSWCNTs; the inset of image (a) shows the retentivity and coercivity in the M-H plot of Co/Ni@SWCNTs; (b) frequency dependence of the real and imaginary parts of the complex permittivity and permeability; (c) effect of thicknesses on the shielding effectiveness $\left(\mathrm{SE}_{\mathrm{A}}\right.$ and $\mathrm{SE}_{\mathrm{R}}$ ) for a composite in the frequency range of $12.4-18 \mathrm{GHz}$ and (d) total SE of Co/Ni@SWCNTs as a function of frequency.

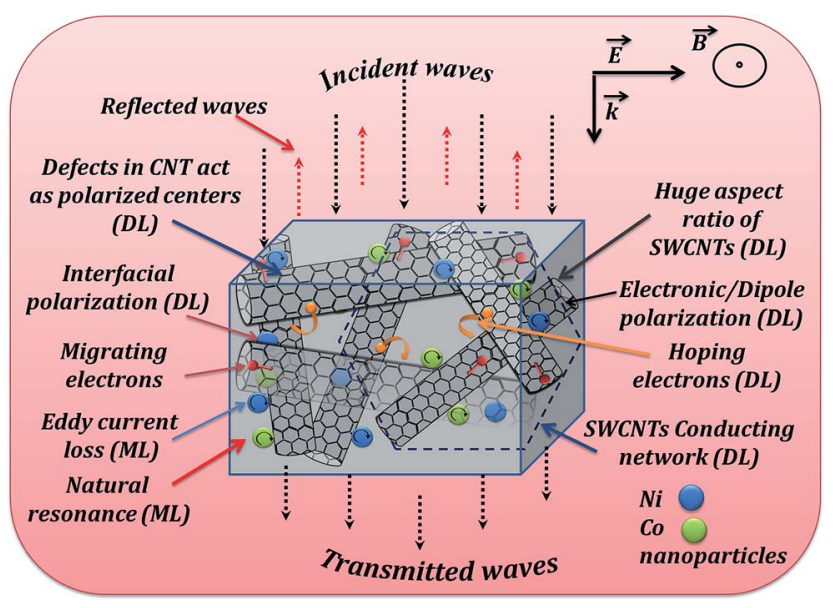

Fig. 4 Schematic presentation of the interaction of EM waves with Co/NiaSWCNTs.

\section{Conclusions}

Cobalt/nickel nanoparticles attached to single-walled carbon nanotubes were successfully synthesized by the dc-arc discharge technique and their dielectric and magnetic performances were investigated. TEM results showed that $\mathrm{Co} / \mathrm{Ni}$ nanoparticles were attached onto SWCNTs. At $15 \mathrm{GHz}$ frequency, a value of 22.7 for dielectric constant, 21.2 for dielectric loss, 1.2 for magnetic permeability and 0.1 for permeability loss were observed for a Co/Ni@SWCNT sample.
At an external applied field of 5 kOe, the saturation magnetization value for the $\mathrm{Co} / \mathrm{Ni} @ S W C N T s$ was $\sim 12.25 \mathrm{emu} \mathrm{g}^{-1}$. A microwave shielding effectiveness value of $24 \mathrm{~dB}$ for a $1.5 \mathrm{~mm}$ thick sample in the frequency range of $12.4-18 \mathrm{GHz}$ was observed which is attributed to dielectric (electronic and interfacial polarization) and magnetic (eddy currents and natural resonances) losses. This new material showed a microwave shielding effectiveness value greater than that required for commercial applications. Thus, these nanocomposites are promising microwave shielding materials in the $\mathrm{Ku}$ band.

\section{References}

1 M.-S. Cao, W.-L. Song, Z.-L. Hou, B. Wen and J. Yuan, The effects of temperature and frequency on the dielectric properties, electromagnetic interference shielding and microwave-absorption of short carbon fiber/silica composites, Carbon, 2010, 48(3), 788-796.

2 T. K. Gupta, B. P. Singh, V. N. Singh, S. Teotia, A. P. Singh, I. Elizabeth, et al., $\mathrm{MnO}_{2}$ decorated graphene nanoribbons with superior permittivity and excellent microwave shielding properties, J. Mater. Chem. A, 2014, 2(12), 42564263.

3 S. Abbas, M. Chandra, A. Verma, R. Chatterjee and T. Goel, Complex permittivity and microwave absorption properties of a composite dielectric absorber, Composites, Part A, 2006, 37(11), 2148-2154. 
4 X. F. Zhang, X. L. Dong, H. Huang, Y. Y. Liu, W. N. Wang, X. G. Zhu, et al., Microwave absorption properties of the carbon-coated nickel nanocapsules, Appl. Phys. Lett., 2006, 89(5), 053115.

5 J. R. Liu, M. Itoh and K.-I. Machida, Electromagnetic wave absorption properties of $\alpha-\mathrm{Fe} / \mathrm{Fe}_{3} \mathrm{~B} / \mathrm{Y}_{2} \mathrm{O}_{3}$ nanocomposites in gigahertz range, Appl. Phys. Lett., 2003, 83(19), 4017-4019.

6 T. Zhao, C. Hou, H. Zhang, R. Zhu, S. She, J. Wang, et al., Electromagnetic Wave Absorbing Properties of Amorphous Carbon Nanotubes, Sci. Rep., 2014, 4, 5619.

7 B. P. Singh, V. Choudhary, P. Saini, S. Pande, V. N. Singh and R. B. Mathur, Enhanced microwave shielding and mechanical properties of high loading MWCNT-epoxy composites, J. Nanopart. Res., 2013, 15(4), 1-12.

8 B. P. Singh, V. Choudhary, P. Saini and R. B. Mathur, Designing of epoxy composites reinforced with carbon nanotubes grown carbon fiber fabric for improved electromagnetic interference shielding, AIP Adv., 2012, 2(2), 022151.

9 R. C. Che, C. Y. Zhi, C. Y. Liang and X. G. Zhou, Fabrication and microwave absorption of carbon nanotubes $/ \mathrm{CoFe}_{2} \mathrm{O}_{4}$ spinel nanocomposite, Appl. Phys. Lett., 2006, 88(3), 033105.

10 T. Narayanan, V. Sunny, M. Shaijumon, P. Ajayan and M. Anantharaman, Enhanced microwave absorption in nickel-filled multiwall carbon nanotubes in the $S$ band, Electrochem. Solid-State Lett., 2009, 12(4), K21-K24.

11 R. C. Che, L. M. Peng, X. F. Duan, Q. Chen and X. L. Liang, Microwave Absorption Enhancement and Complex Permittivity and Permeability of Fe Encapsulated within Carbon Nanotubes, Adv. Mater., 2004, 16(5), 401-405.

12 A. P. Singh, B. K. Gupta, M. Mishra, C. A. Govind, R. B. Mathur, et al., Multiwalled carbon nanotube/cement composites with exceptional electromagnetic interference shielding properties, Carbon, 2013, 56, 86-96.

13 D. Micheli, R. Pastore, C. Apollo, M. Marchetti, G. Gradoni, V. M. Primiani, et al., Broadband Electromagnetic Absorbers Using Carbon Nanostructure-Based Composites. Microwave Theory and Techniques, IEEE Trans., 2011, 59(10), 2633-2646.

14 T. K. Gupta, B. P. Singh, S. R. Dhakate, V. N. Singh and R. B. Mathur, Improved nanoindentation and microwave shielding properties of modified MWCNT reinforced polyurethane composites, J. Mater. Chem. A, 2013, 1(32), 9138-9149.

15 C.-S. Zhang, Q.-Q. Ni, S.-Y. Fu and K. Kurashiki, Electromagnetic interference shielding effect of nanocomposites with carbon nanotube and shape memory polymer, Compos. Sci. Technol., 2007, 67, 2973-2980.

16 Z. Liu, G. Bai, Y. Huang, F. Li, Y. Ma, T. Guo, et al., Microwave Absorptionof Single-Walled Carbon Nanotubes/Soluble Cross-Linked Polyurethane Composites, J. Phys. Chem. C, 2007, 111(37), 13696-13700.

17 Y. Huang, N. Li, Y. Ma, F. Du, F. Li, X. He, et al., The influence of single-walled carbon nanotube structure on the electromagnetic interference shielding efficiency of its epoxy composites, Carbon, 2007, 45(8), 1614-1621.
18 N. Li, Y. Huang, F. Du, X. He, X. Lin, H. Gao, et al., Electromagnetic Interference (EMI) Shielding of SingleWalled Carbon Nanotube Epoxy Composites, Nano Lett., 2006, 6(6), 1141-1145.

19 A. Wadhawan, D. Garrett and J. M. Perez, Nanoparticleassisted microwave absorption by single-wall carbon nanotubes, Appl. Phys. Lett., 2003, 83(13), 2683-2685.

20 R. Kumar Srivastava, T. N. Narayanan, A. P. Reena Mary, M. R. Anantharaman, A. Srivastava, R. Vajtai, et al., Ni filled flexible multi-walled carbon nanotube-polystyrene composite films as efficient microwave absorbers, Appl. Phys. Lett., 2011, 99(11), 113116.

21 L. Saravanan, J. H Liu, H. Y. Miao and L. C. Wang, Preparation and Investigation of Co-Dispersed MWCNT Buckypaper for the Microwave Absorption, Appl. Mech. Mater., 2013, 479-480, 20-24.

22 P. T. Araujo, I. O. Maciel, P. B. C. Pesce, M. A. Pimenta, S. K. Doorn, H. Qian, et al., Nature of the constant factor in the relation between radial breathing mode frequency and tube diameter for single-wall carbon nanotubes, Phys. Rev. B: Condens. Matter Mater. Phys., 2008, 77(24), 241403.

23 A. P. Singh, M. Mishra, A. Chandra and S. K. Dhawan, Graphene oxide/ferrofluid/cement composites for electromagnetic interference shielding application, Nanotechnology, 2011, 22, 9.

24 K. Singh, A. Ohlan, P. Saini and S. K. Dhawan, Poly(3,4ethylenedioxythiophene) $\gamma$-Fe2O3 polymer compositesuper paramagnetic behavior and variable range hopping 1D conduction mechanism-synthesis and characterization, Polym. Adv. Technol., 2008, 19(3), 229-236.

25 V. K. Sachdev, K. Patel, S. Bhattacharya and R. P. Tandon, Electromagnetic interference shielding of graphite/ acrylonitrile butadiene styrene composites, J. Appl. Polym. Sci., 2011, 120(2), 1100-1105.

26 M. Ashokkumar, N. T. Narayanan, B. K. Gupta, A. L. M. Reddy, A. P. Singh, S. K. Dhawan, et al., Conversion of Industrial Bio-Waste into Useful Nanomaterials, ACS Sustainable Chem. Eng., 2013, 1(6), 619-626.

27 A. M. Nicolson and G. F. Ross, Measurement of the intrinsic properties of materials by time-domain techniques, IEEE Trans. Instrum. Meas., 1970, 19, 377-382.

28 Y.-J. Chen, P. Gao, R.-X. Wang, C.-L. Zhu, L.-J. Wang, M.-S. Cao, et al., Porous $\mathrm{Fe}_{3} \mathrm{O}_{4} / \mathrm{SnO}_{2}$ core/shell nanorods: synthesis and electromagnetic properties, J. Phys. Chem. C, 2009, 113(23), 10061-10064.

29 A. P. Singh, M. Mishra, P. Sambyal, B. K. Gupta, B. P. Singh, A. Chandra, et al., Encapsulation of $\gamma-\mathrm{Fe}_{2} \mathrm{O}_{3}$ decorated reduced graphene oxide in polyaniline core-shell tubes as an exceptional tracker for electromagnetic environmental pollution, J. Mater. Chem. A, 2014, 2(10), 3581-3593.

30 X.-X. Wang, M.-M. Lu, W.-Q. Cao, B. Wen and M.-S. Cao, Fabrication, microstructure and microwave absorption of multi-walled carbon nanotube decorated with CdS nanocrystal, Mater. Lett., 2014, 125, 107-110.

31 B. Wen, M.-S. Cao, Z.-L. Hou, W.-L. Song, L. Zhang, M.-M. Lu, et al., Temperature dependent microwave attenuation 
behavior for carbon-nanotube/silica composites, Carbon, 2013, 65, 124-139.

32 M.-S. Cao, J. Yang, W.-L. Song, D.-Q. Zhang, B. Wen, H.-B. Jin, et al., Ferroferric Oxide/Multiwalled Carbon
Nanotube vs. Polyaniline/Ferroferric Oxide/Multiwalled Carbon Nanotube Multiheterostructures for Highly Effective Microwave Absorption, ACS Appl. Mater. Interfaces, 2012, 4(12), 6949-6956. 